\title{
A epistemologia de Humberto Maturana e suas implicaçóes à formaçáo de professores para o ensino de ciências
}

\author{
Evandro Ghedin ${ }^{1}$
}

http://orcid.org/0000-0002-2844-6122

\section{Resumo}

O artigo resulta de pesquisa teórica de caráter ensaístico sobre a proposta de Maturana a questão do conhecimento e suas implicaçóes à formação de professores para o Ensino de Ciências. Metodicamente o ensaio estrutura-se a partir da perspectiva da hermenêutica crítica, constituindo-se em esforço de compreensão fenomenológica da implicação da proposta de Maturana para o campo do ensino e da formação de professores. Embora o autor não tenha pensado sua proposta nessa direção, é possível, ao apropriar-se de seu projeto, transpô-lo para condiçóes que ultrapassam seus objetivos iniciais. Nosso objetivo aqui foi de explicitar a tese central do autor estudado que é: vivemos em um mundo com os outros seres vivos e compartilhamos com eles do processo vital. Por isso, os acontecimentos do mundo que nos cerca não são anteriores à nossa experiência, pois nossa trajetória de vida nos faz construir nosso conhecimento do mundo, sabendo que esse também constrói seu conhecimento a nosso respeito. Assim, podemos afirmar que o conhecimento se dá pela interação do ser vivo com o meio e do meio com o ser vivo, e nesse processo ambos passam por modificaçóes e essas vão alterando por completo nossa condição existencial. $\mathrm{O}$ texto tende a concluir que as reflexóes apresentadas são sempre um convite para que possamos nos questionar sobre o processo de ensino de ciências, ou seja, é uma forma de nos inquietar sobre a forma como estamos fazendo ciências e como estamos ensinando como parte de um processo de formação do humano.

Palavras-chave: Epistemologia, Cognição, Ensino de Ciências, Formação de Professores.

\footnotetext{
${ }^{1}$ Professor Titular-Livre da Faculdade de Educação da Universidade Federal do Amazonas (UFAM). Possui Pósdoutorado em Didática pela Faculdade de Educação da USP (2010). É Doutor em Filosofia da Educação pela USP (2004). Mestre em Educação pela UFAM (2000). Especialista em Antropologia da Amazônia pela UFAM. Especialista em Filosofia e Existência pela Universidade Católica de Brasília (UCB). Graduado em Filosofia pela UCB (1995). Professor Permanente no PPGECEM - Rede Amazônica de Educaçáo em Ciências e Matemática (REAMEC). Professor Permanente no PPGE-UFAM. Professor Permanente no PGEDA Doutorado em Educação na Amazônia - EDUCANORTE. Meus agradecimentos a Maria Roseane Rodrigues (In memoriam) por sua contribuição inicial com esta pesquisa. E-mail: evandroghedin@ufam.edu.br.
} 


\title{
Humberto Maturana's epistemology and its implications for teacher training for science teaching
}

\begin{abstract}
The article is the result of theoretical research of an essayistic nature on Maturana's proposal on the question of knowledge and its implications for the formation of teachers for Science Teaching. Methodically, the essay is structured from the perspective of critical hermeneutics, constituting an effort to phenomenologically understand the implication of Maturana's proposal for the field of teaching and teacher training. Although the author did not think of his proposal in this direction, it is possible, when appropriating his project, to transpose it to conditions that go beyond its initial objectives. Our objective here was to make explicit the central thesis of the studied author, which is: we live in a world with other living beings and share with them the vital process. For this reason, the events in the world around us are not prior to our experience, because our life trajectory makes us build our knowledge of the world, knowing that it also builds its knowledge about us. Thus, we can affirm that knowledge occurs through the interaction of the living being with the environment and between the environment and the living being, and in this process both undergo changes and these completely alter our existential condition. The text tends to conclude that the reflections presented are always an invitation for us to question ourselves about the science teaching process, that is, it is a way to worry about the way we are doing science and how we are teaching as part of a human formation process.
\end{abstract}

Keywords: Epistemology, Cognition, Science Teaching, Teacher Education.

\section{Introduçáo}

A investigação apresentada neste artigo reflete sobre a seguinte questão: quais são as implicaçóes da epistemologia proposta por Humberto Maturana à formação de professores para o Ensino de Ciências? As obras desse autor têm sido muito utilizadas por estudiosos da linguística, antropologia, processos psicoterapêuticos, ciências gerenciais, ciências da informação e estudos de relaçóes humanas em geral e mais recentemente no campo educacional, especialmente considerando suas implicaçôes éticas e os processos de produção do conhecimento.

Nesse sentido, fizemos um esforço para nos apropriar das obras do autor para compreender a epistemologia que ele fomentou e, com essa apropriação, associá-la à formação de professores para o Ensino de Ciências no sentido de construir uma base teórica que auxilie os processos de formação nessa área.

Assim, os professores em contexto de formaçáo acadêmica no Ensino de Ciências ou em formação contínua poderão ter uma ideia básica sobre os conceitos com os quais o autor trabalha a partir desta nossa abordagem refletir 
e vivenciar novas alternativas epistêmicas e metodológicas para o ensino, desenhada para primar, acima de tudo, ao exercício de pensar e repensar constantemente o trabalho docente no contexto da prática pedagógica, internalizando o significado da aceitação mútua e do ato de refletir, como condição de transformação do vivido ao experienciado e do reconhecimento do outro como única possibilidade de construção da identidade individual e coletiva.

Nesse sentido, o objetivo deste artigo é apresentar, demonstrar e discutir as principais ideias de Humberto Maturana de modo a nos fazer perceber de que forma o conhecimento é elaborado e legitimado por ele, como teoria eficaz que contribui para a formação de professores. A fim de alcançar o objetivo pretendido, houve a necessidade, na construção deste artigo, de utilizar na metodologia o enfoque fenomenológico-hermenêutico, o qual possibilitou a compreensão das entrelinhas do pensamento do autor.

Embora haja a preocupação em atingir fundamentalmente a proposta de Maturana, esse não é um estudo completo e nem se pretende que esgote a riqueza do trabalho proposto pelo autor. Considera-se este texto uma introdução a sua obra a partir de uma perspectiva epistemológica, ou seja, sobre os processos e critérios do conhecimento e suas condiçóes cognitivas produzidas como resultado de nosso longo processo evolutivo que se constrói cada vez mais em sua complexidade que envolve a compreensão do cosmos!

É válido ressaltar que o autor, no conjunto de sua obra, descreve exemplos pessoais de uma forma muito particular, permitindo que as situações vividas por ele se concretizem em nosso pensamento à medida que vamos fazendo a análise de seus trabalhos, isso porque seus exemplos são similares aos nossos. Há uma certa universalidade em nossa particularidade, pois participamos de condiçóes comuns que o planeta forjou em nós. Podemos dizer que a complexidade de nossa subjetividade nos é comum, inclusive como condição que tornou possível o conhecimento em nós e nossa condição de ser radicalmente dependente de nossa possibilidade de conhecer.

A apropriação das principais ideias do autor que serviram de base para este trabalho de estudo e pesquisa foi sistematizada a partir de atividades de leitura, fichamentos, análise e interpretação das principais obras de Maturana (2001a; 2001b; 2003; 2005), Maturana e Varela (2001) e Maturana e Rezepka (2000). Há outras obras do autor que pela razão, objetivo e espaço deste texto não foi possível incluí-las, o que demanda um trabalho de análise em continuidade.

$\mathrm{O}$ artigo divide-se em quatro seçóes. A primeira, Conhecer o conhecer, explica esse fenômeno de forma a aceitar a universalidade do fazer no 
conhecer, como problema e ponto de partida para revelar seu fundamento, que é o observador observando o observar. A segunda, Os caminhos explicativos, difunde a legitimidade e a diversidade de domínios de realidade pela reflexão das diferenças por meio de duas maneiras de escutar explicaçôes, que é o caminho da objetividade sem parênteses e o caminho da objetividade entre parênteses. A terceira, Racionalidade e emoçôes, desenvolve a ideia de que todos os sistemas racionais pertencem ao domínio da emoção. A quarta seção, Ciência e vida cotidiana: a ontologia das explicaçóes científicas, aborda A ontologia do observar, que se relaciona com as reflexóes sobre o ser e a sua condição de sujeito do conhecimento que lhe constitui.

\section{Conhecer o conhecer}

O processo de conhecer, na condição de fenômeno cognitivo, é muito mais amplo do que a concepção do pensar, do raciocinar e do medir; aquele se entrelaça em três pontos que o fundamentam como um processo consideravelmente fantástico. $\mathrm{O}$ primeiro ponto é a percepção. O segundo é a emoção. $O$ terceiro é a ação. Todos esses constituem o processo do conhecimento e são essenciais para a vida, caracterizando-se como elementos fundamentais constitutivos da dinâmica vital. Isso indica que o nosso processo de racionalidade, ou a constituição da razão humana emergem da construção de imagens construídas no sistema perceptivo, mediadas pelas emoçóes e operadas pela ação. Portanto, a racionalidade humana não é uma condição já consolidada em nós, mas um tecido bem superficial que pode facilmente ser rompido.

Quanto ao processo de conhecer, Maturana e Varela (2001) demonstram que o ponto de partida para explicá-lo é compreender o que acontece no momento em que o observador está observando o observar. Segundo esses autores, somos observadores observando quando observamos nosso observar em nossa tentativa de descrever e explicar o que fazemos. Nesse contexto, somos sistemas vivos e vivemos na linguagem fazendo o que fazemos, quando explicamos o que fazemos, e já estamos na experiência de observar, quando observamos nosso observar. O observar, portanto, é distinguir na linguagem os diferentes tipos de entidades que trazemos à máo como objetos de nossas descrições, explicaçôes e reflexóes no curso da participação do observador, nas diferentes conversações em que estamos envolvidos no decorrer de nossa vida. 
Maturana e Varela (2001) nos possibilitam experimentar uma nova sensação de perceber o mundo, de forma que, segundo eles, conceber a vida é uma arte de conhecimento. ${ }^{2}$ Dessa forma, para entender o que é a vida, é fundamental compreendermos como os seres vivos conhecem o mundo.

Por conta disso, a tese central proposta pelos autores é: vivemos em um mundo com os outros seres vivos e compartilhamos com eles do processo vital. Nesse sentido, os autores afirmam que os acontecimentos do mundo que nos cerca não são anteriores à nossa experiência, pois nossa trajetória de vida nos faz construir nosso conhecimento do mundo, sabendo que esse também constrói seu conhecimento a nosso respeito. Assim, podemos afirmar que o conhecimento se dá pela interaçáo do ser vivo com o meio e do meio com o ser vivo, e nesse processo ambos passam por modificaçóes.

Concordamos com Maturana e Varela (2001) quando afirmam que em nosso viver defendemos nossas certezas e convicçóes não contestadas, de forma que não existe alternativa para aquilo que nos parece certo, pois percebemos as coisas a partir do nosso olhar, ou seja, a nossa realidade é diferente da realidade do outro, dessa forma, nosso conhecimento sobre nós mesmos e sobre o mundo é um processo que se dá de maneira pessoal por meio de nossas estruturas cognitivas.

As estruturas cognitivas envolvem dois aspectos importantes. O primeiro é o fato de que cada ser humano como ser biológico é formado por estruturas cognitivas individualizadas, logo seu olhar e sua percepção em relação ao mundo será uma experiência vivida com característica peculiar, de maneira que toda sensação será sentida por ele de maneira solitária.

O segundo aspecto é o fato de sermos seres humanos dotados de um sistema nervoso e uma ampla plasticidade cerebral. Isso contribui para a vivência de constantes situaçóes de aprendizagem na interação com os outros seres humanos, por isso é evidente que, em algum momento, nos depararemos afirmando verdades que, no entanto, posteriormente compreenderemos como um equívoco, pois, como seres dotados de estruturas cognitivas determinadas, não podemos distinguir, na experiência, entre ilusão e percepção.

Todavia, podemos dizer que cada um de nós percebe o que se passa à nossa volta, tendo como fundamento a experiência acumulada durante a nossa

\footnotetext{
${ }^{2}$ Maturana (2001a) diz que o conhecimento é uma apreciação de um observador sobre a conduta do outro, que pode ser ele mesmo no momento em que se vê dessa forma, por um lado, descobre-se que o conhecimento é adquirido na convivência. Maturana e Varela (2001, p. 25), afirmam que no "experimento das sombras coloridas”, mostram-nos como nossa experiência está conectada com nossa estrutura biológica e social. O mais evidente é sempre difícil de perceber.
} 
existência, e essa experiência nos modifica. Dessa forma, acreditamos, a priori, que aquilo que vivenciamos, como conhecimento é o que nos importa como verdade.

Nesse sentido, o contexto do "conhecimento do conhecimento" (Maturana; Varela, 2001, p. 267) obriga-nos a adotar uma atitude de contínua atenção contra o fato de afirmarmos ter a certeza do conhecimento, o que se configura em equívoco, visto que devemos reconhecer que essa certeza não é prova das verdades, pois quando conhecemos, não podemos negar que conhecemos, porque o conhecimento nos compromete. Assim, é necessário adotar essa atitude de atenção a fim de nos permitirmos ter a consciência da existência do que sabemos.

Dessa forma, ao analisar o fenômeno do conhecimento e as nossas açóes advindas dele, compreendemos que toda experiência cognitiva inclui o conhecedor de maneira pessoal, arraigado em sua estrutura biológica. Assim, toda experiência de certeza é um fenômeno individual em relação ao ato cognitivo do outro (Maturana; Varela, 2001).

É nesse sentido, referente ao conceito de reflexão, que Maturana e Varela (2001, p. 29) afirmam que ela "é um processo de conhecer como conhecemos, [...] e reconhecer que as certezas e os conhecimentos dos outros são, respectivamente, tão aflitivos e tão tênues quanto os nossos”. Sendo assim, Maturana (2001a) enfatiza a relevância do ser humano como um observador na experiência e como ele procede à explicação do conhecer nessa experiência. Para aprofundar essa questão, analisaremos o modo como o autor nos apresenta os caminhos explicativos.

\section{Os caminhos explicativos}

Os caminhos explicativos são duas formas ou maneiras essenciais que um observador, ao viver uma experiência, pode adotar para escutar ou dar explicaçóes sobre essa experiência vivenciada por ele, que são: "o caminho da objetividade sem parênteses e o caminho da objetividade entre parênteses." (Maturana, 2001b, p. 248, grifos nossos).

No caminho explicativo da objetividade sem parênteses, conhecer é fazer referência a uma realidade independentemente do observador. Maturana (2001b) diz que a existência acontece independentemente do que o observador faz. Dessa forma, as coisas existem quando alguém as conhece ou não; ou se possa vir a conhecê-las, ou se sabe da existência delas por meio da percepção ou da razão. Tais saberes independem da realidade do observador e 
da concretização da existência das coisas. Nesse sentido, uma afirmação cognitiva é válida, porque faz referência a uma realidade independente do observador, ou seja, existe apenas uma realidade que está pronta e acabada, de modo que aceitar uma afirmação cognitiva é valido porque está delimitada apenas na realidade do observador. Assim sendo, nesse caminho explicativo não existem várias afirmaçóes cognitivas em relaçáo à realidade, e sim apenas uma.

Nesse sentido, Maturana (2005) nos revela que o observador não se pergunta pela origem de suas habilidades cognitivas como propriedades constitutivas dele. $\mathrm{O}$ observador aceita a existência de uma realidade que valida o conhecer dele e a explicação decorrente desse conhecimento, de maneira que a universalidade do conhecimento se fundamenta em tal objetividade. Assim, depende de nós mesmos aceitarmos ou não certa formulação da experiência vivenciada por nós a ser explicada, segundo um critério de aceitação de nosso escutar, dessa forma a validade das explicaçôes que aceitamos configura-se em nosso assentimento, e não independente dele.

Dessa forma, somos objetivos porque dizemos que o que falamos é válido, independentemente de nossas crenças. Sendo assim, toda verdade objetiva é universal, ou seja, válida para qualquer observador atrelado a uma realidade de maneira que a cognição dele não permita a aceitação de outras realidades vivenciadas por outros observadores, que, por sua vez, possuem realidades diferentes construídas por meio de outras histórias de vida.

Conforme Maturana (2001b), na objetividade entre parênteses o observador aceita como seus todos os traços constitutivos dos sistemas vivos. Maturana (2001a) afirma que, ao aceitar a pergunta pelo observador e ao assumir a biologia, o observador se dá conta de que cada ser humano é um indivíduo único, formado geneticamente com características peculiares, diferente dos outros seres humanos dotados de estruturas cognitivas individuais e determinadas, que, em virtude disso, possuem percepçóes também diferentes. Nesse sentido, o observador admite que não tenha fundamento experiencial para fazer essa proposição, pois não há mecanismos que permitam dizer que essa é uma proposição válida. Assim, o observador tem de explicar o fenômeno do conhecer.

Para isso, é preciso explicar o que se faz como observador e como é que faz o que se faz; falar de objetos e aceitar que se deve explicar como eles surgem. Para tanto, o observador usa uma linguagem de objeto, fala de uma linguagem de substantivos, do observador, da experiência da linguagem. Nesse contexto, todos são seres entes, ou seja, tudo que se apresenta de maneira concreta, fática ou atual independentemente de, em qualquer nível, tornar-se objeto de 
reflexão, pois fala deles e lida com seres. Sendo assim, seu escutar no explicar é um escutar fazendo referência a entes que existem independentes dele.

Assim, segundo Maturana (2005), explicar é propor uma reformulação da experiência de forma aceitável pelo observador. No momento em que a reformulação da experiência é aceita como uma resposta, ela se constitui em uma explicação para aquele que a aceita. Nesse sentido, escutar uma resposta explicativa, quando não assumimos uma pergunta pela origem das habilidades cognitivas do observador, equivale a escutar esperando ouvir uma referência a uma realidade independente de nós mesmos.

Uma explicação é uma reformulação de uma experiência aceita por um observador, de acordo com critérios de aceitabilidade. Nada é uma explicação em si mesmo, e é a pessoa que aceita uma resposta explicativa quem especifica a resposta como uma explicação. É o escutar do observador voltado para a satisfação do critério de aceitabilidade que determina a que pergunta ele ou ela responde, ao aceitar uma resposta explicativa particular.

Conforme Maturana (2001a), a realidade, quando não é apenas um modo de explicar nossa experiência humana, é aquilo que vivemos como o fundamento do nosso viver. Nessas circunstâncias, a realidade não é energia, não é informação. Nós explicamos nossas experiências com nossas experiências e com as coerências de nossas experiências.

Assim sendo, sobre a explicação da experiência, Maturana e Varela (2001) dizem que ela é sempre uma proposição que reformula ou recria as observaçóes de um fenômeno, em um sistema de conceitos aceitáveis para um grupo de pessoas que compartilham um critério de validação. Nesse processo de aceitação podemos distinguir quatro condições: descrição do fenômeno ou fenômeno a explicar; proposição de um sistema conceitual capaz de gerar o fenômeno a explicar; dedução a partir de proposição de outros fenômenos não explicitamente considerada em sua proposição e observação desses outros fenômenos, deduzidos a partir de proposiçôes.

O critério de validação das explicaçóes da experiência define a ciência como um domínio particular e a constitui como um domínio explicativo. Os cientistas tentam ser consistentes e explícitos em relação a cada uma dessas condiçôes, que constituem etapas fundamentais para a validação das explicações da experiência e registram documentos, criando tradições que vão além de uma pessoa ou geração (Maturana, 2001a). Dessa forma, o marco inicial para gerar uma explicação científica válida é entender o conhecer como ação efetiva. Nesse sentido, para que haja uma ação efetiva, é preciso aceitar uma resposta que se enquadre no sentido da pergunta que se pronunciou, ou seja, é necessário desenvolver uma resposta por meio de critérios 
preestabelecidos sobre uma determinada pergunta fundada a partir dos fenômenos cognitivos.

Quanto à explicação dos fenômenos cognitivos, Maturana e Varela (2001) dizem que ela se localiza na tradição da ciência e se valida por meio de seus critérios. Os fenômenos cognitivos são entendidos como processos pelos quais os significados são originados a partir da estrutura cognitiva do observador de maneira que uma atribuição de significados à realidade em que o indivíduo se encontra é vivida de forma particular.

Assim, os fenômenos cognitivos, como processos de reflexão se configuram em seguimentos nos quais cada significado impulsiona outro significado, de maneira encadeada em busca de uma conclusão, pois segundo Maturana e Varela (2001), conhecer o conhecer não se dispóe como uma árvore com um ponto de partida sólido, que cresce gradualmente até esgotar tudo que há para conhecer; pelo contrário, o conhecimento não se esgota, o que pode acontecer é o conhecedor sofrer alguma perturbação destrutiva, ou seja, morrer e com isso finalizar seu processo cognitivo na condição de ação de conhecer.

\section{Ciência e vida cotidiana: a ontologia das explicaçóes científicas}

Um organismo durante a sua existência sofre modificaçóes em sua estrutura em razão da interação que ele tem com o meio. Nesse sentido, Maturana (2001a) afirma que a história da mudança estrutural desse organismo em interaçôes com o meio é uma deriva - uma deriva estrutural. A ontogenia, ${ }^{3}$ que é a história de transformaçóes de uma unidade, como resultado de uma história de interaçóes, a partir de sua estrutura inicial de um ser vivo, é uma deriva estrutural na qual as mudanças estruturais que ocorrem são contingentes com as interaçôes com o meio. $\mathrm{O}$ meio muda de maneira contingente com as interaçóes com o organismo e, aquilo ao qual o observador se referirá, vai depender de onde esteja seu olhar. Do lugar que ele ocupa como observador em relação ao contexto, ao meio onde ele se encontra.

\footnotetext{
${ }^{3}$ Sobre o determinismo estrutural e linguagem Maturana (2001a, p. 71) diz: “[...] os comportamentos consensuais são condutas que se estabelecem na ontogenia, na história individual dos organismos como resultado do curso particular da ontogenia, e que náo se haveriam estabelecidos se essa ontogenia, se esse curso particular náo houvesse ocorrido. As coordenaçóes consensuais de comportamentos resultam da convivência das transformaçôes dos participantes na convivência, e não haveriam se produzido se não se houvesse produzido essa história de convivência”.
} 
Nesse sentido, falando de mudanças, Maturana (2005) defendeu a ideia de que a história de mudança do cérebro humano está relacionada, principalmente, com a linguagem e seu entrelaçamento com as emoções. Ele sustenta que não há ação humana sem uma emoção que a estabeleça como tal e a torne possível como ato. Observando as ações do outro, conheceremos suas emoçôes como fundamentos que constituem suas ações. Não conheceremos o que poderíamos chamar de seus sentimentos, senão o espaço de existência efetiva em que esse ser humano se move.

Segundo Maturana (2005), a linguagem se estabelece quando se alia ao viver, como modo de viver, esse fluir em coordenaçôes de conduta de coordenaçóes de conduta, que significa o que chamamos de congruência, ou melhor, é quando as palavras ditas estão de acordo com as açôes de quem está dizendo, passando então a existir na convivência como resultado dela. $\mathrm{O}$ fato de nos encontrarmos na linguagem é também algo que ocorre conosco. Ao refletirmos sobre a linguagem, já estamos nela. Nesse sentido, aceitamos nossa capacidade de conhecer como uma condição dada, sem a qual jamais seriamos o que somos enquanto espécie neste planeta.

Dessa forma, Maturana (2001b) diz que existimos na linguagem com o nosso operar, como seres conscientes na reflexão. Diz ainda: "Toda reflexão, inclusive a que se faz sobre os fundamentos do conhecer humano, ocorre necessariamente na linguagem, que é nossa maneira particular de ser humano e estar no fazer humano" (Maturana; Varela, 2001, p. 32).

Assim, para explicarmos a linguagem como "fenômeno biológico", temos de mostrar "é de que maneira ela surge e de que modo na história de interaçóes dos seres vivos essa recursão venha a ter lugar. Além disso, precisamos mostrar também como a linguagem surge na história dos hominídeos (Maturana, 2001a, p. 73).

A palavra ciência, para Maturana (2001a), tem sido usada na história do pensamento ocidental para fazer referência a qualquer conhecimento cuja validade possa ser defendida em bases metodológicas, independentemente do domínio fenomênico no qual é proposto. Hoje em dia, ela é mais frequentemente usada para fazer referência apenas ao conhecimento validado por meio de um método particular, que é o conhecimento científico.

A ciência e a validade das explicaçóes científicas constituem-se na construção de um mundo de ação comensurável com nosso viver. ${ }^{4}$ As

\footnotetext{
4 "Não há dúvida de que frequentemente falamos como se o que vemos como um agente externo incidindo sobre um sistema determinasse o que acontece no sistema sobre o qual ele incide, mas, ao mesmo tempo, sabemos também que isso não é assim. Além disso, a partir de nosso viver cotidiano sabemos também que, ao escutarmos
} 
explicaçóes científicas têm validade, porque têm a ver com as coerências operacionais da experiência no suceder do viver do observador; por isso a ciência tem poder. Elas são proposiçóes gerativas apresentadas no contexto da satisfação do critério de validação, que fazem referência às coerências operacionais do observador, na configuração de um espaço de açóes, nas quais certas operaçóes do observador, no âmbito experiencial, devem ser satisfeitas.

Tudo o que se requer é uma comunidade de observadores-padrão, que gerem afirmaçóes validadas pelo critério de validação descrito anteriormente. As explicações científicas são validadas no domínio de experiências de uma comunidade de observadores, e se relacionam com as coordenaçóes operacionais dos membros dessa comunidade, em circunstâncias nas quais são membros dessa comunidade as pessoas que aceitam e usam esse critério para validar seu explicar (Maturana, 2001b, p. 82).

De acordo com Maturana (2001a), na vida cotidiana agimos sob a compreensão de que a cognição tem a ver com nossas relaçôes interpessoais e coordenaçôes de açôes. Alegamos cognição em outros e em nós mesmos, quando aceitamos as açóes como adequadas, ou seja, as açóes adequadas são respostas com parâmetros preestabelecidos desenvolvidos por meio de indagações. Assim, se for proferida uma indagação e a resposta a essa indagação não corresponder aos critérios preestabelecidos para a resposta esperada, dizemos que não houve uma ação adequada. Logo, não será alegada cognição, pois só há cognição quando houver ação adequada.

Nesse sentido, uma ação adequada é aquela que está de acordo com o que se idealiza como ação. Dessa forma, o conhecimento é entendido como uma constituição feita por um observador, com uma capacidade operacional capaz de atribuir cognição a um sistema vivo, que pode ser ele ou ela própria, ao aceitar suas açóes como adequadas em um domínio cognitivo.

A ciência, como um domínio cognitivo, ${ }^{5}$ é um domínio de açóes, e como tal, é uma rede de conversaçóes que envolvem afirmaçóes e explicaçôes

alguém, o que ouvimos é um acontecer interno a nós, e não o que o outro diz, embora o que ouvimos seja desencadeado por ele ou ela." (Maturana, 2001a, p. 174).

${ }^{5}$ Conforme a Teoria Autopoiética de Maturana e Varela (1995 apud Moraes, 2003) a mente é um processo de conhecer que se confunde com a própria vida. A cognição é compreendida como um fenômeno biológico, pois depende de uma forma ou de outra, das interaçóes de uma ou mais unidades autopoiéticas. Tudo o que acontece na vida de um sistema vivo surge mediante mudanças estruturais. 
legitimadas pelo critério de validação das explicaçôes científicas sob a paixão do explicar. Nesse contexto, Maturana (2001b, p. 45) afirma:

A responsabilidade do cientista está na sua responsabilidade como pessoa. O que acontece é que o cientista gera um domínio especial de conhecimento, um domínio de afirmaçóes que tem características especiais, tem um fundamento no viver. Porque é um modo de explicar a experiência com a experiência, e isso faz com que os cientistas sejam pessoas que estão em pontos nodais de muitos momentos do viver humano moderno.

Não há um único aspecto ou operação do critério de validação das explicaçóes científicas que seja científico por si mesmo. A diferença entre a operação na vida cotidiana como cientistas e como não cientistas depende de emoções, de diferentes desejos de consistência e impecabilidade das açóes e de diferentes desejos de reflexão sobre o que fazemos como cientistas (Maturana, 2001a).

O que torna científico uma explicação ou teoria científica, segundo Maturana (2001a), é o fato de ela ser legitimada pela aplicação do critério de validação das explicaçóes científicas, sem referência à quantificação ou qualquer restrição de domínio. Um observador-padrão pode gerar uma explicação ou teoria científica em qualquer domínio, no qual ele ou ela possa aplicar o critério de validação das explicaçôes científicas.

Maturana (2001b) faz uma reflexáo sobre qual é o problema da cognição. Diz que, quando desejamos saber se alguém sabe algo, lhe fazemos uma pergunta, exigindo que se faça alguma coisa. O problema, então, é identificar a conduta adequada, que satisfaça a quem fez a pergunta. $\mathrm{Na}$ verdade, não temos outra forma de avaliar o conhecimento. A conduta adequada é congruente com as circunstâncias nas quais elas se realizam, e o que se vê são as mudanças de estado de um organismo em seu meio, tal qual vistas por um observador, que descreve essas mudanças.

Duas observaçóes do mesmo sujeito, sob as mesmas condiçóes feitas, com perguntas diferentes podem atribuir diferentes valores cognitivos, o que é visto como o comportamento desse sujeito. Nesse sentido, a avaliação, se há ou não conhecimento, ${ }^{6}$ ocorre sempre em um contexto relacional, em que as mudanças estruturais desencadeadas pelas perturbaçóes aparecem para um

\footnotetext{
${ }^{6}$ Maturana (2001b) diz que o conhecimento é um comportamento aceito como adequado por um observador num domínio particular que ele ou ela especifica. Da mesma maneira, há tantos domínios cognitivos diferentes quantos critérios diferentes que o observador possa usar para aceitar um comportamento adequado.
} 
observador, como um efeito sobre o ambiente. É em relação ao efeito esperado que o observador avalia as mudanças estruturais, que são desencadeadas no organismo como um ato cognitivo (Maturana; Varela, 2001).

Conforme Maturana (2001a), o uso de explicaçóes científicas pelos membros de uma comunidade de observadores-padrão define e constitui a ciência como um domínio cognitivo. Ontologicamente, nessa forma de constituição, a ciência é como um domínio de ações definidas por um critério de validação ou aceitabilidade usado por um observador ou pelos membros de uma comunidade de observadores, para aceitar aquelas ações como válidas, em um domínio de ações definidas por esse mesmo critério de aceitabilidade.

Segundo Maturana (2001a), o conhecimento científico tem de ser aceito como universalmente válido, já que as explicaçóes e afirmaçóes que pertencem ao conhecimento científico são validadas por meio de contínua confrontação com uma realidade objetiva independente. As peculiaridades da ciência como domínio cognitivo surgem de sua forma de constituição pela aplicação do critério de validação das explicaçôes científicas.

O fato de a ciência, como um domínio cognitivo, ser constituída e validada nas coerências operacionais da práxis de viver dos observadores-padrão ao funcionarem em seus domínios experienciais sem referência a uma realidade independente não torna as afirmaçôes científicas subjetivas (Maturana, 2001a, p. 147).

As noçóes de objetividade e universalidade na ciência podem ser utilizadas de maneiras diferentes e, ao mesmo tempo, mais relevantes para a prática da ciência. $\mathrm{O}$ critério de validação das explicações científicas pode ser explicitado de maneira operacional e não implica nenhuma referência direta ou indireta de uma realidade, pois independe do mundo objetivo; esse pode ser apreendido, usado e aplicado com total independência das crenças do observador-padrão sobre a realidade, sobre os valores e sobre a vida espiritual.

A ciência como domínio cognitivo ${ }^{7}$ traz à mão a existência em seu domínio de existência, distinguindo a si própria como em um sistema vivo. Transforma-se ao mudarem as perguntas que o observador-padrão faz,

\footnotetext{
${ }^{7}$ Sobre o fenômeno da cognição Maturana (2001a), fala do experimento da salamandra feito em 1943 e questiona: o que é que acontece quando o observador vê um bichinho, fora da salamandra, e ela lança a língua e o captura? $\mathrm{O}$ que é isto de dizer que há um bichinho lá no momento que a salamandra lança a língua? Concluiu que o sistema nervoso funciona com correlaçóes internas. Novamente, a pergunta é: como é se encontrar num mundo ordenado manipulando, náo tropeçando a cada instante, e no qual a maior parte do tempo náo se comete erros na companhia dos demais?
} 
conforme as explicaçóes que ele ou ela aceita, e essas perguntas e explicaçóes modificam-se ao mudar seu domínio de experiências no fluir de sua práxis de viver de maneira criativa. Dessa maneira, a criatividade é considerada como um julgamento feito por um observador que, de acordo com seu escutar, atribui caráter inovador às atividades, operações ou distinçóes de outro observador, que pode também ser ele ou ela própria.

Nesse contexto, a criatividade fundamenta-se como um elemento primordial, para que possamos viver na experiência e no fluir de sermos sistemas vivos. Como afirma Maturana (2001a), a criatividade é algo que acontece em nós e a nós, à medida que linguajamos, pois o fato de existirmos na linguagem e de não podermos existir fora dela não é uma limitação em nós, mas é a condição que torna possível a ciência como um domínio explicativo, tal que tudo que nela produzimos torna-se parte do nosso existir como seres humanos.

\section{Reflexáo sobre as implicaçóes da epistemologia de Humberto Maturana à formaçáo de professores para o Ensino de Ciências.}

As implicações da epistemologia proposta por Humberto Maturana à formação de professores para o Ensino de Ciências estão fundamentadas em três aspectos trabalhados pelo autor que são: a percepção que é o ato e efeito de perceber as coisas; a emoção, que são disposiçôes corporais dinâmicas dos domínios de ações que operamos em um instante; a ação, ou seja, é tudo o que fazemos em qualquer domínio operacional.

A importância desses aspectos para a formação de professores ao Ensino de Ciências diz respeito ao fato de que esses aspectos fundamentam o processo do conhecimento. Nesse sentido, é imprescindível que o professor, por lidar essencialmente com a questão do conhecimento, esteja sempre informado de seus processos e do avanço de sua condição como possibilidade de desenvolvimento humano mediado pelo ensino e que compreenda suas questóes centrais.

Nessa perspectiva, o processo formativo do professor, lhe coloca a condição fundamental de um observador que observa o próprio observador que, pela ação, faz a experiência de viver e transformar o vivido em experiência mediada pela reflexáo, esta constituinte da condição de seu processo cognitivo integrante da possibilidade de acesso ao conhecimento do mundo, somente possível quando se desloca do lugar de observador para posicionar-se no lugar do observador que observa o observador de um dado objeto real que se 
configura diante de si em objeto de representação e abstração, sem a qual não é possível saber o que se passa e o que passa diante de si. Assim, não se trata de repetir a experiência do outro, mas de fazer a própria experiência, onde nasce o mais genuíno do conhecer que produz o ser. Experiência necessária a todos os seres cuja condição de ser é radicalmente dependente do conhecer.

Maturana e Rezepka (2000) acreditam que a maior dificuldade no processo educacional está entre duas classes de fenômenos: a formação humana e a capacitação. Segundo eles, a formação humana relaciona-se com o desenvolvimento da pessoa de maneira que seja capaz de ser cocriadora com outros de um espaço humano de convivência social, por isso a formação humana consiste em criar condiçôes para o crescimento da pessoa no autorrespeito e no respeito pelo outro, cuja individualidade, identidade e confiança se fundamentam no respeito por si mesmo.

Quanto à capacitação, diz respeito à aquisição de habilidade e capacidade de ação como recursos operacionais para realizar o que quiser viver, por isso a capacitação como tarefa educacional consiste na criação de espaços de ação nos quais se exercitem as habilidades que se deseja desenvolver, criando um âmbito de ampliação das capacidades de fazer na reflexão sobre como se deseja viver.

É nesse sentido, que a formaçáo de professores para o Ensino de Ciências deve fundamentar-se no pensamento de Maturana e Rezepka, pois segundo eles a formação humana e a capacitação são fenômenos importantes para os professores dominarem de maneira que sejam aptos a desenvolverem um processo educacional que vá além da transmissão de conteúdos, isto é, a formação de valores.

Pensando assim, podemos reafirmar o que Maturana e Rezepka (2000, p. 15) dizem sobre:

A separação conceitual das conversaçôes de formação humana e capacitação permite, no entanto, duas coisas: primeira, treinar as emoçóes e o entendimento do professor ou da professora, de modo que possa sempre se relacionar com seus alunos na biologia do amor e interagir com eles sem corrigir seu ser; segunda, criar um espaço de conhecimentos reflexivos e capacidades de ação no professor ou na professora, de modo que possam, por sua vez, guiar seus alunos na contínua ampliação de seus conhecimentos reflexivos e de sua capacidade de ação apenas corrigindo o seu fazer e não o seu ser (grifos nosso). 
Nesse contexto, consideramos que as ideias de Maturana são imprescindíveis para serem desenvolvidas no Ensino de Ciências, de maneira que podemos dizer que, quando os representantes de todos os países estiverem com os olhos no destino da humanidade, desenvolver-se-á uma consciência planetária e uma pedagogia voltada para a formação integral do professor.

Para que isso aconteça, é preciso revisar conceitos sobre o universo, o ser humano, o progresso e a evolução voltados para a sustentabilidade. Segundo Moraes (2003), a consolidação de um quadro epistêmico implica a maneira como pensamos, sentimos e atuamos em relação aos nossos hábitos, valores, atitudes e estilos de vida.

A partir do pensamento de Varela e Flores (2003 apud Moraes, 2003) podemos refletir que é preciso pensar no futuro, olhar o momento histórico em que estamos vivendo para compreendermos a potencialidade desta época. Precisamos compreender que uma educação transformadora necessita em primeiro lugar de professores que sejam capazes de ajudar o estudante a aprender a conhecer, a conhecer como se aprende e a viver/conviver na mudança a fim de que possa sobreviver às incertezas e ao inesperado.

É nesse sentido que o trabalho do professor é de fundamental, pois realiza nele mesmo esse processo quanto está em formação e constrói, no espaço da escola a condição necessária para que cada estudante possa fazer o processo de viver a experiência de constituir-se um ser que amplia a consciência de si a medida em que realiza em si tal processo.

Percepção, emoção e ação constituem-se as condições biológicas do conhecer. Elas constituem os pressupostos para a reflexão, consciência e autonomia, que realiza a inteligência no humano de forma diferenciada dos outros seres biológicos, pois nos humanos, em contexto sistemático de conhecimento, na relação com o ambiente e os outros humanos se realiza um salto qualitativo no processo do conhecer, pois o conhecer altera a condiçáo do ser que altera a si mesmo pela experiência que realiza mediada pela linguagem.

Somente por ela o pensamento pode assumir a sua materialidade, pois é só quando um pensamento pode ser dito, no interior de uma interlocução, que se realiza, no sentido de que somente pela linguagem a abstração adquire materialidade. É nessa condição de reflexividade que a vida se torna experiência que ultrapassa o próprio vivido para expressar-se como experienciado. $\mathrm{O}$ que significa dizer refletido no espelho da reflexividade.

O conhecer emerge da própria biologia que o produziu no interior do planeta, mas ultrapassa essa condição quando a razáo se produz como camada sobreposta e essa condição biológica, formando uma nova que camada que 
institui outros processos cognitivos que o humano foi produzindo sobre si mesmo nos últimos três milhóes de anos.

Como a observação da nossa racionalidade só emerge quando ela própria se sente pronta, nos últimos cinquenta mil anos, somente agora nos damos conta da biologia que sustenta a possibilidade da racionalidade dada pelo conjunto de processos cognitivos básico e superiores que instituem no humano sua condição de ser na dependência do conhecer a si, as coisas e ao próprio processo de conhecer o próprio conhecer.

Portanto, refletir sobre as ações como condição de conhecer o processo do conhecer e sua estrutura constitui pré-requisito para o professor, pois realiza no estudante processo análogo Sobre isso, Maturana e Varela (2001) nos dizem que estamos estruturalmente acoplados às circunstâncias e ao mundo em que vivemos, e nossa sobrevivência física, mental, psíquica e emocional depende desse acoplamento e de processos codeterminados, e o que acontece com o sujeito influencia o que ocorre na estrutura do objeto e viceversa.

A teoria autopoiética de Maturana e Varela (2001) nos mostra que temos de mudar com as mudanças do mundo para continuar existindo. Assim, todo sistema vivo necessita de muita flexibilidade estrutural para dar conta das perturbaçôes, desafios e problemas e se reorganizar sempre que necessário. Nessa teoria, não existe um meio separado. Os processos de conhecer e aprender são processos autopoiéticos que se autorreproduzem, envolvendo a totalidade do ser humano. Além disso, destaca o papel das emoções e dos sentimentos na maneira como os humanos evoluem, destacando suas influências na qualidade da ação e da reflexão.

O olhar autopoiético da teoria oferece um esboço científico coerente com o novo pensamento científico e supera a visão cartesiana do funcionamento dos sistemas vivos que constituem o universo. Reconhece que mente e matéria são dimensões do fenômeno da vida e o processo de cognição é o próprio processo da vida. Reconhece ainda a importância do processo de interação do sistema nervoso, imunológico e endócrino.

É nessa direção que o ensino de ciências precisa caminhar, pois, pela compreensão de Maturana, o aprender teria de ser algo diferente de captar um objeto externo, já que, em um processo interativo, o que se passa a um indivíduo depende de sua estrutura cognitiva, de sua ação e atuação sobre o meio ambiente. $\mathrm{O}$ fenômeno da educação e da aprendizagem é também um fenômeno de transformação na convivência e o aprender se dá na transformação estrutural que ocorre com a convivência social. 
Segundo Moraes (2003), em 1956, Maturana começou a investigar a organização da vida e como os organismos vivos se auto-organizam, reproduzem-se e evoluem. Concentrou sua atenção na ocorrência do fenômeno da percepçáo. Depois de seu doutorado desenvolvido na Universidade de Harvard, voltou-se para as áreas de neuroanatomia e fisiologia da visão.

Conforme a teoria de Maturana, um sistema estruturalmente acoplado é um sistema de aprendizagem. Um vai compensando o outro, que vai aprendendo a viver/conviver com o outro. É um sistema em que ocorrem constantes processos de adaptação, de aprendizagem e de desenvolvimento, indicando, assim, que o conhecimento tem uma base biológica e se constrói, tendo como base ontológica o mundo físico.

Nesse sentido, a tarefa da educação é formar seres humanos para o presente, capazes de pensar e fazer tudo o que é preciso como um ato responsável por meio de sua consciência social. Esse é o fundamento de todo o processo educativo, para refletir sobre sua atividade e seu refletir, de ver e corrigir erros, de cooperar e de possuir um comportamento ético, porque tal posicionamento não desaparece em suas relaçóes com os outros.

Maturana e Rezepka (2000) dizem que sob o olhar autopoiético, educar e aprender são fenômenos biológicos fundamentais que envolvem todas as dimensôes do viver humano em total integração do corpo com o espírito. $\mathrm{O}$ aprender implica transformar-se em coerência com o emocionar e resulta de uma história de interaçóes recorrentes, em que dois ou mais sistemas vivos interagem.

Nesse sentido, a formação do professor para o Ensino de Ciências há que permitir que ele veja as próprias emoçóes como o espaço de habilitação em que se encontra em cada momento sem perder o respeito por si mesmo. Isso requer liberdade reflexiva e confiança em suas capacidades.

Essa confiança é possível como um ato harmônico no viver, reconhecendo, desde sua intimidade, que todos os seres humanos são igualmente inteligentes e capazes de aprender tudo que o outro ser humano pode fazer. Para que isso aconteça, deve-se criar um espaço que valorize a atividade de maneira não competitiva, mas um espaço de ação/reflexão e de convivência que possibilite o fazer e o conviver por meio de uma educação fundada na biologia do amor, "no encanto do ver, do ouvir, do cheirar, do tocar e do refletir, descobrindo o que há no seu entorno" (Moraes, 2003, p. 125).

Nesse contexto, a ação e a reflexão deveriam vir juntas, modulando-se recursivamente no viver. A reflexão alteraria o curso do fazer e colocaria a 
atenção do "fazedor" no âmbito da ética para ser consciente de sua responsabilidade em seu fazer. A pedagogia, nessa maneira de pensar, implica a criação de contextos flexíveis, em que a reflexão permite o diálogo, a qualidade da aprendizagem e do conhecimento produzido.

Permite, ainda, a criação de ambientes cooperativos e solidários, despertando a curiosidade, a sensibilidade e a percepção, levando cada um a analisar os efeitos e a qualidade do trabalho que desenvolve e, ao mesmo tempo, tendo uma visão de conjunto da evolução de todo o processo.

\section{Consideraçóes Finais}

Esse estudo nos proporcionou uma forma diferente de ver o mundo em relação ao que estamos acostumados a ver. Os exemplos dados pelo autor para fazer a analogia a sua teoria e a natureza de sua formação acadêmica nos permitem entender, não sem uma relativa dificuldade, que o conhecimento em nós emerge de uma condição biológica e se realiza em uma condição situacional que se dá em relaçáa com o outro o que, como efeito de solidariedade, produz a possibilidade, ou sua ilusão, da superação da nossa condição biológica quando estamos no conhecer.

Por isso, devemos considerar, portanto, que a fenomenologia biológica tratada por Maturana em relação às nossas experiências não devem tomar outro rumo que náo seja a conceituação da linguagem e da cognição como atividades que observamos no espaço de interaçóes em que vivemos. Portanto, os melhores processos de investigação para avaliar o desenvolvimento da própria cognição é vê-la em ação, em contexto de ação, agindo nas interações com os outros sujeitos cognitivos.

Este estudo possui dois limites, que contraditoriamente constituem duas possibilidades.

A primeira é que este estudo nos deu a possibilidade de decidirmos se queríamos desaprender o que tínhamos aprendido como seres humanos e sobre o humano em sua cognição mediada pela linguagem como expressão da reflexão, pois Maturana nos apresenta, com sua linguagem particular, outra perspectiva de viver, que tem como principal fundamento de aprendizagem a aceitação do outro como um legítimo outro na convivência, sem o qual náo sabemos bem quem somos, pois o outro constitui nosso horizonte de identidade.

A segunda é o fato de que a epistemologia desse autor está construída por meio de fenômenos cognitivos e biológicos. Há necessidade de 
desenvolver um estudo mais aprofundado no sentido de compreender a proposta que ele nos apresenta como teoria do conhecimento. Isso exige um aprofundamento necessário para podermos avançar na compreensão de sua proposta de entender o conhecer como caminho biológico que a evolução nos dotou e da qual não podemos fugir.

As ideias de Maturana podem ser consideradas revolucionárias na medida em que abrem uma perspectiva ampla e múltipla, que inclui várias áreas científicas entre elas a Biologia, a Física, a Sociologia, a Antropologia, a Administração de empresas, a Epistemologia, a Ética, a Psicologia e a Pedagogia embutidas nessa teoria.

O entrelaçamento dessas disciplinas resultou de um novo olhar ao trabalho de Maturana propiciado pela aceitação, cada vez maior, da biologia do conhecimento. Essa é uma afirmativa que se confirma nas três das principais obras em que o autor propóe-se discutir a cognição. Por esse motivo a obras A Árvore do Conhecimento é considerada uma das obras mais importantes do século XX, justamente por apresentar as bases biológicas da compreensão humana proporcionando uma gama de explicaçôes coerentes sobre descobertas importantes no processo de cognição.

Maturana, ao contrário de muitos cientistas, preocupa-se com a construção do conhecimento e com todos os processos que precisamos percorrer para alcançar tal construção de forma consistente e consciente, visando à busca de um mundo melhor. As reflexóes profundas apresentadas por esse autor são sempre um convite para que possamos nos questionar sobre o processo de ensino de ciências, ou seja, é uma forma de nos inquietar sobre a forma como estamos fazendo ciências e como estamos ensinando como parte de um processo de formação do humano.

A peculiaridade com a qual Maturana nos apresenta suas reflexóes sobre cognição nos desperta interesse, pois o autor deixa claro em suas obras que vivencia o que defende em suas teorias e nos fala com propriedade que todo fazer humano fundamenta a compreensão de duas dimensóes adicionais do ser humano, ou seja, a responsabilidade e a liberdade, pois para o autor somos responsáveis no momento em que, em nossa reflexão, nos damos conta se queremos ou náo as consequências de nossas açốes, e, portanto, uma vez livres no momento em que refletimos sobre nosso fazer, nos damos conta se queremos ou não queremos nosso querer e as possíveis consequências advindas desse querer, e também nos damos conta de que nosso querer ou não querer as consequências de nossas açóes pode mudar nosso desejar ou não desejar tais consequências, o que altera o rumo das coisas. 
As reflexóes do autor nos questionam radicalmente sobre o modo como ensinamos ciências e sobre as consequências operadas na vida de quem ensinamos. A forma como se ensina atende uma perspectiva ampla e inovadora nos modos de compreender o conhecer e o modo como operamos com tal processo no contexto do ensino de ciências e no espaço da formação de professores.

Maturana afirma que ciência e vida cotidiana não podem ser separadas, pois, a validação da ciência acontece justamente nas ações do cotidiano, então conforme o próprio autor insiste, faz-se necessário que atentemos para as nossas açóes cotidianas e que nos questionemos para que náo permaneçamos na "deliciosa ignorância".

\section{Referências}

MATURANA, H. R. Cogniçâo, ciência e vida cotidiana. Belo Horizonte: Ed. da UFMG, 2001a.

. A ontologia da realidade. Belo Horizonte: Ed. da UFMG, $2001 \mathrm{~b}$.

. Emoçôes e linguagem na educação e na política. 4. ed. Belo Horizonte: Ed. da UFMG, 2005.

MATURANA, H. R; REZEPKA, S. N. Formação humana e capacitação. Petrópolis, RJ: Vozes, 2000.

MATURANA, H.; VARELA, F. J. A árvore do conhecimento: as bases biológicas da compreensão humana. São Paulo: Palas Athena, 2001.

MORAES, Maria C. Educar na biologia do amor e da solidariedade. Petrópolis, RJ: Vozes, 2003.

Recebido em: 29 ago. 2020

Aceito em: 02 dez. 2020 